\title{
Sinopulmonary Complications in Subjects With Primary Immunodeficiency
}

\author{
Abdullah Owayed MD and Waleed Al-Herz MD
}

\begin{abstract}
BACKGROUND: The aim of this work was to describe the frequency and spectrum of sinopulmonary complications among subjects with primary immunodeficiency disorders. METHODS: The subjects included all patients with primary immunodeficiency who were registered prospectively between January 2004 and December 2013 in the Kuwait National Primary Immunodeficiency Disorders Registry. RESULTS: A total of 202 subjects were registered during the study period. Subjects with combined immunodeficiencies were the most prevalent (65 subjects, $32.1 \%$ ), followed by well-defined syndromes with immunodeficiency (45 subjects, $22.2 \%$ ) and predominantly antibody deficiencies ( 35 subjects, $17.3 \%$ ). A total of 295 sinopulmonary manifestations were observed in 127 subjects $(63 \%)$; 157 manifestations $(\mathbf{5 3 . 2 \%})$ were observed among the presenting symptoms, and 138 manifestations $(\mathbf{4 6 . 8 \%})$ occurred after establishment of the primary immunodeficiency disorder diagnosis. Sinopulmonary manifestations were more common in subjects with predominantly antibody deficiencies (2.3 manifestations/subject), followed by subjects with combined immunodeficiencies (1.75 manifestations/subject). Pneumonia was the most common manifestation (108 episodes affecting 80 subjects), followed by otitis media (81 episodes affecting 59 subjects), bronchiectasis in 28 subjects $(13.8 \%)$, and asthma in 22 subjects (11\%). Microbial organisms were isolated during 46 episodes of pneumonia (42.5\%) (cytomegalovirus and Pneumocystis jirovecii were the most common). There were 57 deaths $(28 \%)$ during the study period. Twenty-four deaths $(42 \%)$ were due to pulmonary complications as follows: pneumonia (16 subjects, $8 \%$ ), pulmonary hemorrhage (6 subjects, $3 \%$ ), and aspiration pneumonia ( 2 subjects, $1 \%$ ). CONCLUSIONS: Sinopulmonary complications are common in subjects with primary immunodeficiency. They can be serious and continue to occur even after proper treatment is initiated. The pulmonologist should play an important role in the management of subjects with primary immunodeficiency disorder. Key words: primary immunodeficiency; pneumonia; bronchiectasis; asthma; complications. [Respir Care 2016;61(8):1067-1072. (C) 2016 Daedalus Enterprises]
\end{abstract}

\section{Introduction}

Primary immunodeficiency disorders are a heterogeneous group of genetic defects in the immune system. ${ }^{1-4}$

\footnotetext{
Drs Owayed and Al-Herz are affiliated with the Department of Pediatrics, Faculty of Medicine, Kuwait University, Kuwait City, Kuwait. Dr Owayed is also affiliated with the Pulmonary Unit, Department of Pediatrics, Mubarak Hospital, Kuwait City, Kuwait. Dr Al-Herz is also affiliated with the Allergy and Clinical Immunology Unit, Department of Pediatrics, Al-Sabah Hospital, Kuwait City, Kuwait.
}

The Kuwait National Primary Immunodeficiency Registry is supported by Kuwait Foundation for the Advancement of Sciences Grant 20101302-05. The authors have disclosed no conflicts of interest.
Patients with primary immunodeficiency disorders are more likely to experience recurrent, serious, and unusual infections and have a tendency to develop a wide range of complications..$^{5-7}$ The true incidence and prevalence of primary immunodeficiency disorders are not known. However, it is now clear that primary immunodeficiency disorders are not as rare as originally assumed several decades ago. The upper estimates suggest that 6 million people

\footnotetext{
Correspondence: Waleed Al-Herz MD, Department of Pediatrics, Faculty of Medicine, Kuwait University, 24923 Safat, Zip code 13110, Kuwait. E-mail:wemh@hotmail.com.
}

DOI: $10.4187 /$ respcare. 04479 
worldwide may be living with a primary immunodeficiency disorder. ${ }^{8}$ Despite the increasing numbers of primary immunodeficiency disorders diagnosed in the last decade ${ }^{9}$ and a better understanding of immune system functions, many physicians lack knowledge regarding these disorders and do not often consider the possibility of immunodeficiency early enough in the differential diagnosis, ${ }^{10,11}$ resulting in a significant delay in diagnosis and an increased morbidity and mortality. ${ }^{12-18}$

Primary immunodeficiency disorder in Kuwait, a small country located in the Arabian Peninsula, is relatively common with a prevalence of 11.98 in 100,000 children, an incidence of 10.06 in 100,000 children, and an estimated occurrence of 1 in 1,000 live births. ${ }^{12}$ This is much higher than the reported prevalence in populations from other ethnicities or geographical regions (eg, 4.4 in 100,000 in France, ${ }^{19} 5.6$ in 100,000 in Australia, ${ }^{20} 1.51$ in 10,000 in Germany, ${ }^{21}$ and 2.3 in 100,000 in Japan ${ }^{22}$ ). The high prevalence of primary immunodeficiency disorder in Kuwait is probably caused by the high rate of consanguineous marriages among our population. ${ }^{23}$ The aim of this study was to describe the frequency and spectrum of sinopulmonary complications among subjects with primary immunodeficiency disorders registered in the Kuwait National Primary Immunodeficiency Disorders Registry.

\section{Methods}

\section{Subjects With Primary Immunodeficiency Disorders}

This longitudinal, prospective clinical study was conducted between January 2004 and December 2013 and included all of the patients registered in the Kuwait National Primary Immunodeficiency Registry, which was approved by the Research and Ethics Committee of the Ministry of Health in Kuwait. The subjects were classified according to both clinical and laboratory criteria for primary immunodeficiency disorders reported in 2011 by the International Union of Immunological Societies Primary Immunodeficiency Diseases Committee. ${ }^{24}$ The possibility of secondary immunodeficiencies (drug-induced, HIV-induced, and immunodeficiency associated with metabolic disorders, among others) was eliminated by obtaining a detailed history and by performing the appropriate testing when these disorders were suspected. The immunological tests performed for our subjects were done using standard techniques and included complete blood count with peripheral blood smear evaluation, serum immunoglobulins, antibody response to previous vaccines, lymphocyte phenotype (T, B, and NK cells) by flow cytometry, lymphocyte stimulation test, autoantibodies, nitro blue tetrazolium dye test, and complement hemolytic activity (CH50) with specific complement component when needed.

\section{QUICK LOOK}

\section{Current knowledge}

Patients with primary immunodeficiency are more likely to experience a wide range of complications. Unfortunately, many physicians lack knowledge regarding primary immunodeficiency and do not often consider the possibility of immunodeficiency early enough in the differential diagnosis, resulting in a significant delay in diagnosis and an increased morbidity and mortality.

\section{What this paper contributes to our knowledge}

Sinopulmonary complications are common in subjects with primary immunodeficiency. They can be serious and continue to occur even after proper treatment is initiated.

\section{Results}

A total of 202 subjects were registered during the study period. Combined immunodeficiencies were the most prevalent (65 subjects, $32.1 \%$ ), followed by well-defined syndromes with immunodeficiency (45 subjects, $22.2 \%$ ); predominantly antibody deficiencies (35 subjects, 17.3\%); diseases of immune dysregulation (30 subjects, $15 \%$ ); congenital defects of phagocyte number, function, or both (14 subjects, $7 \%$ ); complement deficiencies (9 subjects, $4.4 \%$ ); and autoinflammatory disorders (4 subjects, $2 \%$ ). One hundred eight subjects $(53.4 \%)$ were treated with intravenous immunoglobulins, $106(52.5 \%)$ were treated with prophylaxis antimicrobial agents, and 49 (24\%) received hematopoietic stem cell transplantation.

A total of 295 sinopulmonary manifestations were observed in 127 subjects (63\%). One hundred fifty-seven $(53.2 \%)$ of the manifestations were among the presenting symptoms, and 138 (46.8\%) occurred after establishment of the primary immunodeficiency disorder diagnosis. Table 1 shows the frequency of sinopulmonary manifestations according to each primary immunodeficiency disorder category. These manifestations were more common in subjects with predominantly antibody deficiencies (2.3 manifestations/subject), followed by those with combined immunodeficiencies (1.75 manifestations/subject). Pneumonia was the most common manifestation (108 episodes affecting 80 subjects), followed by otitis media ( 81 episodes affecting 59 subjects), bronchiectasis affecting 28 subjects (13.8\%), and asthma affecting 22 subjects (11\%) (Table 2). Five subjects (2.5\%) (4 with signal transducer and activator of transcription 3 deficiency and one with severe combined immunodeficiency) had pneumonia that was complicated by pneumatocele. Microbial organisms 


\section{Sinopulmonary Complications in Subjects With PID}

Table 1. Subjects' Characteristics and Frequency of Sinopulmonary Manifestations According to Each Primary Immunodeficiency Category

\begin{tabular}{|c|c|c|c|c|c|c|c|}
\hline PID Category & $\begin{array}{c}n(\%) \\
\text { Males/Females }\end{array}$ & $\begin{array}{c}\text { Mean } \\
\text { Onset } \\
\text { Age, mo }\end{array}$ & $\begin{array}{c}\text { Mean } \\
\text { Diagnosis } \\
\text { Age, mo }\end{array}$ & $\begin{array}{l}\text { IVIG, } n \\
(\%)\end{array}$ & $\begin{array}{l}\mathrm{HSCT}, n \\
(\%)\end{array}$ & $\begin{array}{l}\text { No. of } \\
\text { Sinopulmonary } \\
\text { Manifestations } \\
\text { (total 295) }\end{array}$ & $\begin{array}{l}\text { No. of } \\
\text { Sinopulmonary } \\
\text { Manifestations/ } \\
\text { Subject }\end{array}$ \\
\hline Combined immunodeficiencies & $65(32.1 \%), 35 / 30$ & 5.65 & 17.98 & $59(91 \%)$ & $35(54 \%)$ & 114 & 1.75 \\
\hline $\begin{array}{l}\text { Well-defined syndromes with } \\
\text { immunodeficiency* }\end{array}$ & $45(22.2 \%), 24 / 21$ & 5.69 & 30.80 & $5(11 \%)$ & $2(4.5 \%)$ & 50 & 1.1 \\
\hline Predominantly antibody deficiencies & $35(17.3 \%), 24 / 11$ & 83.17 & 130.77 & $22(63 \%)$ & 0 & 80 & 2.3 \\
\hline Diseases of immune dysregulation & $30(15 \%), 16 / 14$ & 18.33 & 38.60 & $11(36 \%)$ & $9(30 \%)$ & 29 & 0.9 \\
\hline $\begin{array}{l}\text { Congenital defects of phagocyte } \\
\text { number, function or both }\end{array}$ & $14(7 \%), 6 / 8$ & 5.00 & 16.36 & $4(28.5 \%)$ & $3(21 \%)$ & 10 & 0.71 \\
\hline Autoinflammatory disorders $\dagger$ & $4(2 \%), 4 / 0$ & 0.25 & 30.5 & 0 & 0 & 0 & 0 \\
\hline Complement deficiencies & $9(4.4 \%), 2 / 7$ & 42.78 & 158.00 & 0 & 0 & 12 & 1.3 \\
\hline \multicolumn{8}{|c|}{$\begin{array}{l}\text { * Wischott-Aldrich syndrome, DiGeorge syndrome, STAT3 deficiency, ataxia-telangiectasia, and hepatic veno-occlusive disease with immunodeficiency. } \\
\dagger \text { interleukin-10 deficiency. } \\
\text { PID = primary immunodeficiency disorder } \\
\text { IVIG = intravenous immunoglobulins } \\
\text { HSCT = hematopoietic stem cell transplantation }\end{array}$} \\
\hline
\end{tabular}

Table 2. Number of Subjects With the Most Frequently Observed Sinopulmonary Manifestations According to the Primary Immunodeficiency Disorder Categories

\begin{tabular}{|c|c|c|c|c|}
\hline PID Category & Pneumonia $(n=80)$ & Otitis media $(n=59)$ & Bronchiectasis $(n=28)$ & Asthma $(n=22)$ \\
\hline Combined immunodeficiencies & $32(49.2)$ & $22(33.8)$ & $7(10.7)$ & $9(13.8)$ \\
\hline $\begin{array}{l}\text { Well-defined syndromes with } \\
\text { immunodeficiency* }\end{array}$ & $12(26.6)$ & $7(15.5)$ & $2(4.4)$ & $5(11.1)$ \\
\hline Predominantly antibody deficiencies & $21(60)$ & $21(60)$ & $12(34.2)$ & $6(17.1)$ \\
\hline Diseases of immune dysregulation & $8(26.6)$ & $8(26.6)$ & $3(10)$ & $2(6.6)$ \\
\hline $\begin{array}{l}\text { Congenital defects of phagocyte number, } \\
\text { function or both }\end{array}$ & $3(21.4)$ & $1(7.1)$ & $0(0)$ & $0(0)$ \\
\hline Autoinflammatory disorders $\dagger$ & $0(0)$ & $0(0)$ & $0(0)$ & $0(0)$ \\
\hline Complement deficiencies & $4(44.4)$ & $0(0)$ & $4(44.4)$ & $0(0)$ \\
\hline \multicolumn{5}{|c|}{$\begin{array}{l}\text { Data are } n(\%) \text {. } \\
\text { * Wischott-Aldrich syndrome, DiGeorge syndrome, STAT3 deficiency, ataxia-telangiectasia, and hepatic veno-occlusive disease with immunodeficiency. } \\
\dagger \text { interleukin-10 deficiency. } \\
\text { PID = primary immunodeficiency disorder }\end{array}$} \\
\hline
\end{tabular}

were isolated during 46 pneumonia episodes $(42.5 \%)$ as follows: cytomegalovirus (16 episodes), Pneumocystis jirovecii (9 episodes), Klebsiella pneumoniae (3 episodes), adenovirus, parainfluenza Epstein-Barr virus, H1N1, and Aspergillus fumigatus (2 episodes each), respiratory syncytial virus, herpes simplex virus, varicella, rhinovirus, Enterobacter cloacae, stenotrophomonas, Enterococcus faecalis, and Streptococcus pneumoniae (one episode each). Table 3 shows miscellaneous sinopulmonary manifestations according to specific primary immunodeficiency disorder diseases.

There were 57 deaths $(28 \%)$ during the study period. Twenty-four deaths (42\%) were due to pulmonary complications as follows: pneumonia (16 subjects, $8 \%$ ), pulmonary hemorrhage (6 subjects, $3 \%$ ), and aspiration pneumonia (2 subjects, $1 \%)$.

\section{Discussion}

This study presents the frequency and spectrum of sinopulmonary complications among subjects with primary immunodeficiency disorders. Furthermore, it describes the distribution of specific sinopulmonary manifestations according to primary immunodeficiency disorder categories as well as the sequence of appearance of various sinopulmonary complications in relation to the primary immunodeficiency disorder diagnosis.

Sixty-three percent of the reported subjects suffered from various sinopulmonary complications, with approximately 1.5 manifestations/subject. More than half of the complications were among the presenting symptoms. Sinopulmonary complications continued to occur even after establishment of the primary immunodeficiency disorder 


\section{Sinopulmonary Complications in Subjects With PID}

Table 3. Miscellaneous Sinopulmonary Manifestations According to Specific Primary Immunodeficiency Disorder Diseases

\begin{tabular}{|c|c|}
\hline Sinopulmonary Manifestations & PID Diagnosis $(n)$ \\
\hline \multirow[t]{6}{*}{ Sinusitis $(n=12)$} & ZAP-70 deficiency (1) \\
\hline & $\begin{array}{l}\text { Agammaglobulinemia with no B } \\
\text { cells (1) }\end{array}$ \\
\hline & AID deficiency (3) \\
\hline & Selective IgA deficiency (3) \\
\hline & CVID (3) \\
\hline & STAT3 deficiency (1) \\
\hline \multirow{5}{*}{$\begin{array}{l}\text { Interstitial lung diseases } \\
\quad(n=6)\end{array}$} & RAG2 deficiency (1) \\
\hline & $\begin{array}{l}\text { Agammaglobulinemia with no B } \\
\text { cells (1) }\end{array}$ \\
\hline & CVID (1) \\
\hline & Immundysregulation (1) \\
\hline & PAP (2) \\
\hline \multirow[t]{4}{*}{ Pulmonary nodules $(n=4)$} & CGD (1) \\
\hline & DiGeorge syndrome (1) \\
\hline & Immundysregulation (1) \\
\hline & AID deficiency (1 patient) \\
\hline $\begin{array}{l}\text { Lymphocytic interstitial } \\
\text { pneumonitis }\end{array}$ & STAT5b deficiency (2) \\
\hline Laryngeal web & DiGeorge syndrome (1) \\
\hline Sunglottic stenosis & DiGeorge syndrome (1) \\
\hline $\begin{array}{l}\text { Pulmonary graft versus } \\
\text { host disease }\end{array}$ & $\begin{array}{l}\text { MHC II deficiency and stem cell } \\
\text { transplant (1) }\end{array}$ \\
\hline $\begin{array}{l}\text { Allergic bronchopulmonary } \\
\text { aspergillosis }\end{array}$ & DOCK8 deficiency (1) \\
\hline Alveolar haemorrhage & SCID and stem cell transplant (1) \\
\hline Aspiration pneumonia & SCID (2) \\
\hline \multicolumn{2}{|l|}{$\overline{\text { PID }=\text { primary immunodeficiency disorder }}$} \\
\hline \multicolumn{2}{|c|}{$\mathrm{ZAP}-70=$ zeta-chain-associated protein kinase 70} \\
\hline \multicolumn{2}{|l|}{ AID $=$ activation-induced deaminase } \\
\hline \multicolumn{2}{|l|}{$\mathrm{CVID}=$ common variable immunodeficiency } \\
\hline \multicolumn{2}{|c|}{ STAT3 $=$ signal transducer and activator of transcription 3} \\
\hline \multicolumn{2}{|c|}{ RAG2 $=$ recombination-activating gene 2} \\
\hline \multicolumn{2}{|l|}{$\mathrm{PAP}=$ pulmonary alveolar proteinosis } \\
\hline \multicolumn{2}{|c|}{ STAT $5 \mathrm{~b}=$ signal transducer and activator of transcription $5 \mathrm{~b}$} \\
\hline \multicolumn{2}{|c|}{$\mathrm{MHC}=$ major histocompatibility complex } \\
\hline \multicolumn{2}{|l|}{$\begin{array}{l}\text { DOCK8 }=\text { dedicator of cytokinesis } 8 \\
\text { SCID = severe combined immunodeficiency }\end{array}$} \\
\hline SCID $=$ severe combined immunodeficien & \\
\hline
\end{tabular}

diagnosis. This observation is in agreement with previous findings showing that despite the use of appropriate treatment, many subjects with primary immunodeficiency disorder continue to develop acute and chronic infections as well as many noninfectious complications. ${ }^{25,26}$ Lung diseases significantly impacted the quality of life of subjects with some types of primary immunodeficiency disorder ${ }^{27}$ and were common causes of death in another group of subjects with primary immunodeficiency disorder. ${ }^{28}$ Forty-two percent of the deaths that occurred during the current study period were due to sinopulmonary complications. Accordingly, pulmonologists should play an active role in the care of patients with primary immunodeficiency disorder. These patients should also be closely monitored and screened regularly for lung complications so that early
Table 4. Warning Signs of Primary Immunodeficiencies in Children

$\geq 4$ new ear infections within 1 y

$\geq 2$ serious sinus infections within $1 \mathrm{y}$

$\geq 2$ mos. on antibiotics with little effect

$\geq 2$ episodes of pneumonia within 1 y

Failure of an infant to gain weight or grow normally

Recurrent, deep skin or organ abscesses

Persistent thrush in mouth or fungal infection on skin

Need for intravenous antibiotics to clear infections

Two or more deep-seated infections, including septicemia

A family history of primary immunodeficiency

If a child is affected by $\geq 2$ warning signs, he or she should be examined for possible primary immunodeficiency.

and aggressive interventions can be initiated to avoid significant morbidity and mortality.

Sinopulmonary complications were more common in subjects with predominantly antibody deficiencies compared with the other categories. A possible explanation for this is that the disease severity in this primary immunodeficiency disorder category is less compared with other primary immunodeficiency disorder categories, and thus patients live longer with a greater chance of developing various complications. Another explanation for such a finding is that in comparison with other primary immunodeficiency disorder categories, patients with predominantly antibody deficiencies have very low $\operatorname{IgA}$, which is important for mucosal immunity as in the respiratory and gastrointestinal tracts. As expected, infections were the most common sinopulmonary manifestations in our cohort, which is consistent with previous reports. ${ }^{29}$ In a previous study, $14 \%$ of the subjects who presented with recurrent pneumonia were found to have an underlying immune disorder. ${ }^{30}$ Because respiratory infections are common in general, physicians should be alerted about the proper indications to work up patients for the possibility of primary immunodeficiency disorders. For this purpose, the Jeffery Model Foundation has published 10 warning signs ${ }^{31}$ (Tables 4 and 5). However, these signs should only be used as guidance. For example, a neonate presenting with a first episode of pneumonia caused by $P$. jirovecii should be worked up for possible primary immunodeficiency disorder without waiting for the second episode to develop.

We were able to identify the causative pathogen in 46 episodes of pneumonia, facilitating the use of targeted antimicrobial agents. As observed in our cohort, the pathogens that cause respiratory infectious complications in primary immunodeficiency disorder display a typical spectrum according to the immune defect. ${ }^{29}$ This observation should aid in the diagnostic approach in an attempt to identify a particular type of primary immunodeficiency disorder. For example, patients with combined immunodeficiencies are prone to develop respiratory infections 


\section{Sinopulmonary Complications in Subjects With PID}

Table 5. Warning Signs of Primary Immunodeficiencies in Adults

$\geq 2$ new ear infections within $1 \mathrm{y}$

$\geq 2$ new sinus infections within $1 \mathrm{y}$, in the absence of allergy

1 pneumonia/y for more than $1 \mathrm{y}$

Chronic diarrhea with weight loss

Recurrent viral infections (colds, herpes, warts, condyloma)

Recurrent need for intravenous antibiotics to clear infections

Recurrent, deep abscesses of the skin or internal organs

Persistent thrush or fungal infection on the skin or elsewhere

Infection with normally harmless tuberculosis-like bacteria

A family history of primary immunodeficiency

If an adult is affected by $\geq 2$ warning signs, he or she should be examined for possible primary immunodeficiency.

caused by a wide range of bacteria, fungi, and viruses, whereas patients with predominantly antibody deficiencies are at risk of developing bacterial respiratory infections. Patients with phagocytic defects, however, are prone to developing respiratory infections caused by bacteria and fungi.

Bronchiectasis affected only $13.8 \%$ of the presented subjects. It was more common in predominantly antibody deficiencies (34.2\%), which is in agreement with previous studies, and affected $37 \%$ of the subjects with common variable immunodeficiency ${ }^{32}$ and $32 \%$ of those with $\mathrm{X}$-linked agammaglobulinemia. ${ }^{27}$ In a recent review, ${ }^{33}$ primary immunodeficiency disorder was the cause of bronchiectasis in $16 \%$ of non-cystic fibrosis subjects. Accordingly, any patient who presents with bronchiectasis should be worked up for primary immunodeficiency disorder. Additionally, patients with primary immunodeficiency disorder, particularly those suffering from predominantly antibody deficiencies, should be regularly screened for bronchiectasis using high-resolution computed tomography. ${ }^{34}$

Asthma affected only $11 \%$ of our cohort, whereas its prevalence in our population was found to exceed $15 \% .{ }^{35}$ This could be due to underreporting of symptoms or underdiagnosis. Four subjects presented with pulmonary nodules, which were associated with granulomatous diseases affecting other organs (spleen, liver, and gut). Two subjects with signal transducer and activator of transcription 5 b deficiency had lymphocytic interstitial pneumonitis, which is a known complication of this disease. ${ }^{36}$

There are some limitations of this work despite the fact that it is a longitudinal prospective study. The age of the development of sinopulmonary complication and the time of occurrence after establishing primary immunodeficiency disorder diagnosis are not available in our registry data. Furthermore, not all subjects with infectious sinopulmonary complication had extensive testing to identify the causative microbial agents. In addition, screening spirometry and high-resolution computed tomography of the chest were not done in all subjects suffering from predominantly antibody deficiencies.

\section{Conclusions}

In the present study, we presented the frequency of sinopulmonary manifestations in subjects with primary immunodeficiency disorder who were included in a national registry prospectively over a period of $10 \mathrm{y}$. It is important to perform similar studies in subjects with primary immunodeficiency disorder who are of different ethnicities and from various geographic areas as well as in subjects with specific primary immunodeficiency disorder diseases. This strategy will facilitate a better understanding of pathophysiologic factors underlying the occurrence of sinopulmonary complications in primary immunodeficiency disorder such that appropriate measures can be undertaken in a timely manner to avoid morbidity and mortality. Due to the high frequency and severity of such complications, pulmonologists should play an important role in the management of patients with primary immunodeficiency. This role will be facilitated by an awareness of the classification and mechanisms of primary immunodeficiency disorder and their associated pulmonary complications.

\section{ACKNOWLEDGMENTS}

We thank all of the physicians, scientists, and support staff who contributed to the care of the patients with primary immunodeficiency disorder. We are grateful to the patients and their families for their valuable contribution to the Kuwait National Primary Immunodeficiency Registry.

\section{REFERENCES}

1. Routes J, Abinun M, Al-Herz W, Bustamante J, Condino-Neto A, De La Morena MT, et al. ICON: the early diagnosis of congenital immunodeficiencies. J Clin Immunol 2014;34(4):398-424.

2. Ochs HD, Hagin D. Primary immunodeficiency disorders: general classification, new molecular insights, and practical approach to diagnosis and treatment. Ann Allergy Asthma Immunol 2014;112(6): 489-495.

3. Griffith LM, Cowan MJ, Notarangelo LD, Kohn DB, Puck JM, Pai SY, et al. Primary Immune Deficiency Treatment Consortium (PIDTC) report. J Allergy Clin Immunol 2014;133(2):335-347.

4. Ochs HD, Hitzig WH. History of primary immunodeficiency diseases. Curr Opin Allergy Clin Immunol 2012;12(6):577-587.

5. O'Sullivan MD, Cant AJ. The 10 warning signs: a time for a change? Curr Opin Allergy Clin Immunol 2012;12(6):588-594.

6. Al-Herz W, Nanda A. Skin manifestations in primary immunodeficient children. Pediatr Dermatol 2011;28(5):494-501.

7. Rezaei N, Hedayat M, Aghamohammadi A, Nichols KE. Primary immunodeficiency diseases associated with increased susceptibility to viral infections and malignancies. J Allergy Clin Immunol 2011; 127(6):1329-1341.e2.

8. Bousfiha AA, Jeddane L, Ailal F, Benhsaien I, Mahlaoui N, Casanova JL, Abel L. Primary immunodeficiency diseases worldwide: more common than generally thought. J Clin Immunol 2013;33(1): $1-7$. 


\section{Sinopulmonary Complications in Subjects With PID}

9. Platt C, Geha RS, Chou J. Gene hunting in the genomic era: approaches to diagnostic dilemmas in patients with primary immunodeficiencies. J Allergy Clin Immunol 2014;134(2):262-268.

10. Al-Herz W, Zainal ME, Salama M, Al-Ateeqi W, Husain K, AbdulRasoul M, et al. Primary immunodeficiency disorders: survey of pediatricians in Kuwait. J Clin Immunol 2008;28(4):379-383.

11. Al-Hammadi S, Al-Reyami E, Al-Remeithi S, Al-Zaabi K, Al-Zir R, Al-Sagban $\mathrm{H}$, et al. Attentiveness of pediatricians to primary immunodeficiency disorders. BMC Res Notes 2012;5:393-394.

12. Al-Herz W. Primary immunodeficiency disorders in Kuwait: first report from Kuwait National Primary Immunodeficiency Registry (2004-2006). J Clin Immunol 2008;28(2):186-193.

13. Ludviksson BR, Sigurdardottir ST, Johannsson JH, Haraldsson A, Hardarson TO. Epidemiology of primary immunodeficiency in Iceland. J Clin Immunol 2014 [Epub ahead of print].

14. Kobrynski L, Powell RW, Bowen S. Prevalence and morbidity of primary immunodeficiency diseases, United States 2001-2007. J Clin Immunol 2014;34(8):954-961.

15. Aghamohammadi A, Mohammadinejad P, Abolhassani H, Mirminachi B, Movahedi M, Gharagozlou M, et al. Primary immunodeficiency disorders in Iran: update and new insights from the third report of the national registry. J Clin Immunol 2014;34(4):478-490.

16. Bousfiha AA, Jeddane L, El Hafidi N, Benajiba N, Rada N, El Bakkouri J, et al. First report on the Moroccan registry of primary immunodeficiencies: 15 years of experience (1998-2012). J Clin Immunol 2014;34(4):459-468.

17. Gathmann B, Mahlaoui N, CEREDIH, Gérard L, Oksenhendler E, Warnatz K, et al. Clinical picture and treatment of 2212 patients with common variable immunodeficiency. J Allergy Clin Immunol 2014; 134(1):116-126.

18. Al-Herz W, Moussa MA. Survival and predictors of death among primary immunodeficient patients: a registry-based study. J Clin Immunol 2012;32(3):467-473.

19. CEREDIH: The French PID study group. The French national registry of primary immunodeficiency diseases. Clin Immunol 2010; 135(2):264-272

20. Kirkpatrick P, Riminton S. Primary immunodeficiency diseases in Australia and New Zealand. J Clin Immunol 2007;27(5):517-524.

21. Gathmann B, Goldacker S, Klima M, Belohradsky BH, Notheis G, Ehl S, et al. The German national registry for primary immunodeficiencies (PID). Clin Exp Immunol 2013;173(2):372-380.

22. Ishimura M, Takada H, Doi T, Imai K, Sasahara Y, Kanegane H, et al. Nationwide survey of patients with primary immunodeficiency diseases in Japan. J Clin Immunol 2011;31(6):968-976.

23. Al-Herz W, Naguib KK, Notarangelo LD, Geha RS, Alwadaani A. Parental consanguinity and the risk of primary immunodeficiency disorders: report from the Kuwait National Primary Immunodeficiency Disorders Registry. Int Arch Allergy Immunol 2011;154(1): 76-80.

24. Al-Herz W, Bousfiha A, Casanova JL, Chapel H, Conley ME, Cunningham-Rundles C, et al. Primary immunodeficiency diseases: an update on the classification from the international union of immunological societies expert committee for primary immunodeficiency. Front Immunol 2011;2:54.

25. Lucas M, Lee M, Lortan J, Lopez-Granados E, Misbah S, Chapel H. Infection outcomes in patients with common variable immunodeficiency disorders: relationship to immunoglobulin therapy over 22 years. J Allergy Clin Immunol 2010;125(6):1354-1360.e4.

26. Chapel H, Lucas M, Lee M, Bjorkander J, Webster D, Grimbacher $\mathrm{B}$, et al. Common variable immunodeficiency disorders: division into distinct clinical phenotypes. Blood 2008;112(2):277-286.

27. Howard V, Greene JM, Pahwa S, Winkelstein JA, Boyle JM, Kocak M, Conley ME. The health status and quality of life of adults with X-linked agammaglobulinemia. Clin Immunol 2006;118(2):201-208.

28. Resnick ES, Moshier EL, Godbold JH, Cunningham-Rundles C. Morbidity and mortality in common variable immune deficiency over 4 decades. Blood 2012;119(7):1650-1657.

29. Jesenak M, Banovcin P, Jesenakova B, Babusikova E. Pulmonary manifestations of primary immunodeficiency disorders in children. Front Pediatr 2014;2:77.

30. Owayed AF, Campbell DM, Wang EE. Underlying causes of recurrent pneumonia in children. Arch Pediatr Adolesc Med 2000;154(2): 190-194.

31. Jeffrey Modell Foundation. 10 Warning Signs. http://www.info4pi.org/ library/educational-materials/10-warning-signs. Accessed October 31, 2015.

32. Oksenhendler E, Gérard L, Fieschi C, Malphettes M, Mouillot G, Jaussaud R, et al. Infections in 252 patients with common variable immunodeficiency. Clin Infect Dis 2008;46(10):1547-1554.

33. Brower KS, Del Vecchio MT, Aronoff SC. The etiologies of non-CF bronchiectasis in childhood: a systematic review of 989 subjects. BMC Pediatr 2014;14:4

34. Verma N, Grimbacher B, Hurst JR. Lung disease in primary antibody deficiency. Lancet Respir Med. 2015;3(8):651-660.

35. Owayed A, Behbehani N, Al-Momen J. Changing prevalence of asthma and allergic diseases among Kuwaiti children: an ISAAC study (phase III). Med Princ Pract 2008;17(4):284-289.

36. Nadeau K, Hwa V, Rosenfeld RG. STAT5b deficiency: an unsuspected cause of growth failure, immunodeficiency, and severe pulmonary disease. J Pediatr 2011;158(5):701-708. 